\title{
Risk Factors for Failure in Double-Plate Tube Surgery for Refractory Glaucoma: 25 Years Surgical Experience
}

This article was published in the following Dove Press journal: Clinical Ophthalmology

\section{Susana Duch (iD \\ Carlos A Arciniegas- \\ Perasso (D) \\ Stefania Piludu \\ Shirin Djavanmardi \\ Elena Milla}

Department of Ophthalmology, Innova Ocular ICO-Barcelona, Barcelona, Spain
Correspondence: Susana Duch Innova Ocular ICO Barcelona, c/Fco Carbonell 42 AT, Barcelona, 08034, Spain Tel +34-629370919

Email sdt1237654@gmail.com
Purpose: To investigate risk factors associated with success and failure in double-plate tube surgery.

Methods: This retrospective case-series observational study included 243 consecutive eyes that underwent anterior-segment double-plate tube surgery from 1990 to 2015. Evaluation of the efficacy of the device was based on the final intraocular pressure (IOP) and the need for anti-glaucoma medication. We also assessed success and failure according to risk factors for trabeculectomy and an early hypertensive phase (HP).

Results: Preoperative IOP was $37.3 \pm 13.1 \mathrm{mmHg}(\mathrm{mean} \pm \mathrm{SD})$ with $3.0 \pm 0.7$ medications. After a median follow-up of 44.3 months, the mean IOP was $14.6 \pm 6.3 \mathrm{mmHg}$ with $0.4 \pm 1.0$ medications. The final IOPs ranged from 6 to $21 \mathrm{mmHg}$ in $87.24 \%$ of eyes; however, $25.47 \%$ required medication. No risk factors studied were associated with surgical failure. Preoperative IOP, glaucoma type, previous surgery, previous anti-glaucoma drugs, implant type, and HP were associated with partial success $(\mathrm{p}<0.05)$. HP and preoperative use of brimonidine reduced the probability of complete success by $66.9 \%$ and $68.2 \%$, respectively $(\mathrm{p}<0.05)$. HP was more likely when chronic preoperative prostaglandin analogues were administered (odds ratio [OR] 4.286; 95\% confidence intervals [CI] 1.593-11.529; $\mathrm{P}=0.0039)$ and when the tube was located in the posterior chamber (OR 3.561; 95\% CI 1.286-9.861; $\mathrm{P}=0.0145$ ).

Conclusion: Tube surgery is effective and seems to be independent of the major risk factors for glaucoma surgery. However, previous surgery and some chronic preoperative drugs are related to the need for glaucoma medication to achieve the target pressure.

Keywords: glaucoma drainage implants, tube shunt, double-plate Molteno implant, glaucoma surgery, hypertensive phase, refractory glaucoma

\section{Summary Guidelines}

Risk factors associated with trabeculectomy failure were analysed in Double-plate implant surgery by reviewing a large cohort of patients operated over a 25 -year period.

Double-plate drainage implants are effective in controlling intraocular pressure (IOP) in refractory glaucoma and seems to be independent of the major risk factors for glaucoma surgery. However, prior ocular surgery and some chronic preoperative drugs are related to the need for glaucoma medication to achieve the target IOP.

\section{Introduction}

Glaucoma drainage devices (GDDs) were introduced to control intraocular pressure (IOP) in cases of refractory glaucoma where standard filtering procedures were 
expected to fail, but since the tube versus trabeculectomy study (TVT) showed a higher success rate for tube surgery over trabeculectomy in eyes with previous filtering and/or cataract surgery, there has been an increase in indications for GDD surgery in almost all clinical settings, except as primary surgery in naive eyes with open-angle glaucoma and healthy conjunctival status. ${ }^{1-4}$

Even though both techniques share the complex cell turnover during their bleb and capsular maturation, the filtration capsule of GDDs has different morphologic features and responds differently to anti-mitotic drugs. ${ }^{5-8}$ In addition, there is no early postoperative hypertensive phase (HP) after trabeculectomy or any other filtering surgery except for GDDs.

The main cause of the failure of filtering glaucoma surgery remains filtering bleb obliteration due to subconjunctival scarring. The factors responsible are those that stimulate subconjunctival fibrotic proliferation, which varies widely between patients and may be genetic, acquired, or a combination of both. Among the acquired causes are the prolonged use of ocular hypotensive drops that cause long-term ocular surface toxicity, especially those containing preservatives such as benzalkonium chloride, the preoperative intraocular inflammatory status, or the sum of previous intraocular surgeries. ${ }^{9}$ However, it is still unclear which preoperative conditions predict the final results of GDD, as little is known about the risk factors for the failure of drainage implants and whether the same risk factors as for trabeculectomy should be considered.

The aim of this study was to analyse the risk factors for GDD surgical outcomes and their association with the HP by review of a large cohort of patients operated on by our department. The patients evaluated had been operated on in a period of 25 years by the same surgeon using the same surgical technique and protocol and assuming that certain differences have been derived from the different follow-up time of the patients.

\section{Methods}

We performed a retrospective 25 -year consecutive caseseries observational study to analyse the impact of trabeculectomy risk factors on the success of double-plate implant surgery. The study adhered to the tenets of the Declaration of Helsinki and institutional review board approval, from our institution (Hospital Universitario de Bellvitge, L'Hospitalet, Spain) was obtained: document 11/16, Ref\# EPA031/16. Data confidentiality and consent for data review was signed by the patients on their first visit at the clinic following the laws in force in Spain.

Eyes from adults with glaucoma who had undergone anterior-segment, over or below the iris, superior double-plate implant surgery (Double-plate Molteno [DPM], Ophthalmic Ltd., Dunedin, New Zealand or Double-plate silicone implant [DPSI] FCI S.A.S, Paris, France) by the same surgeon (SD) between 1990 and 2015 were included. Both implants have the same size and design but different plate material. Eyes with follow-up $<3$ months, clinically relevant missing data, or a follow-up performed in other clinics were excluded.

All devices were implanted in the upper quadrants by passing the second plate beneath the superior rectus muscle under retrobulbar anaesthesia and sedation. Topical 5-fluorouracil $(50 \mathrm{mg} / \mathrm{mL})$ was applied in all cases by impregnating the scleral surface with a sponge. A 23-gauge needle entry was made toward the anterior or posterior chamber, according to the surgeon's criteria. A $6 / 0$ polyglactin ligature was used as a complete flow restrictor. In eyes with advanced glaucoma in which the preoperative IOP exceeded 40 $\mathrm{mmHg}$, tube fenestrations or orphan trabeculectomy was performed to prevent high IOP immediately after surgery.

Alcohol-preserved donor scleral graft was used to cover the extraocular portion of the tube. Neovascular glaucoma (NVG) cases underwent pan-retinal photocoagulation, peripheral retinal cryotherapy, or anti-VGEF intraocular injections according to the retina specialist's criteria, prior to GDD implantation.

Postoperative treatment consisted of tobramycin + dexamethasone drops $3 \mathrm{mg} / \mathrm{mL}+1 \mathrm{mg} / \mathrm{mL}$ (Tobradex ${ }^{\circledR}$, Novartis Farmacéutica, S.A., Barcelona, Spain) and dexamethasone $1 \mathrm{mg} / \mathrm{mL}$ drops (Dexametasona ${ }^{\circledR}$, Novartis Farmacéutica, S.A., Barcelona, Spain) three times daily administered together with the preoperative hypotensive medication. Once the tube ligature was released, topical dexamethasone was tapered over 2 months until the eye was quiescent. HP was treated with topical and subconjunctival steroids, oral carbonic anhydrase inhibitors, and other hypotensive ophthalmic drops when needed.

\section{Primary and Secondary Outcomes}

Primary outcomes were the rate of surgical success and failure based on the achievement of target IOP with or without glaucoma medication. Qualified success (QS) was defined as an IOP ranging from 6 to $21 \mathrm{mmHg}$ and a $20 \%$ decrease in IOP, with (partial success [PS]) or without (complete success [CS]) the need for anti-glaucoma medication. Failure was defined as an IOP $>21 \mathrm{mmHg}$ or lack 
of IOP reduction by at least $20 \%$ from baseline, an IOP of $\leq 5 \mathrm{mmHg}$ resulting from the implant, the need for additional glaucoma surgery, or removal of the GDD.

Secondary outcomes included the presence and impact of known risk factors for filtering surgical failure upon GDD success rate, the development of HP defined as a sudden and reversible increase in IOP $(>30 \mathrm{mmHg}) 2$ to 4 weeks after the tube opening and initiation of percolation of the aqueous humour through the tube (not being caused by GDD malfunction), and the contribution of surgical technique variations (plate material and intraocular location of the tube) to the final result. ${ }^{10}$

In eyes with complications unrelated to the GDD, the last IOP before the development of the complication was recorded for the study analysis and the follow-up was discontinued.

The statistical analyses were performed using the SPSS software (IBM SPSS Statistics, Version 24). The groups were compared using the Student's $t$-test or the Wilcoxon and $\mathrm{chi}^{2}$ or Fisher's exact test for continuous and categorical variables. Multivariate logistic regression was performed to identify risk factors associated with failure, complete and partial success, and the HP event. A $p$ value of $<0.05$ was considered statistically significant.

\section{Results}

We studied 243 consecutive eyes of 240 Caucasian adults with a mean follow-up of $66.8 \pm 64$ months (mean $\pm \mathrm{SD}$ ).
The demographic data (Table 1) showed no association with failure or the need for medication at the end of the follow-up.

NVG was the most frequent aetiology (88 eyes, $36.2 \%$ ), mainly due to diabetic retinopathy (45 eyes, $60.0 \%)$, followed by central retinal vein occlusion $(21$ eyes, 28\%), carotid artery ischemia (4 eyes, 5.3\%) and other causes ( 5 eyes, 6.6\%). All implants had a similar double-plate design and size but, with respect to the material, DPM has polymethyl methacrylate (PMM) plates and was used in 99 eyes while DPSI with silicon plates was implanted in 144 eyes. The tube was located over the iris in the anterior chamber or below the iris in the posterior chamber in 53.1\% (129 eyes) and $46.9 \%$ (114 eyes), respectively. Tube fenestrations and orphan trabeculectomy were performed in two and one eyes, respectively.

The mean preoperative IOP of $37.3 \pm 13.1 \mathrm{mmHg}$ with 3 \pm 1 glaucoma medications fell to a final mean postoperative IOP of $14.6 \pm 6.3 \mathrm{mmHg}$ and $0.4 \pm 1$ medications. At the end of the follow-up, 31 eyes (12.8\%) had failed. In the QS group, the mean postoperative IOP was $13.4 \pm 4 \mathrm{mmHg}$. In this group, CS was achieved in 159 (65.4\%) eyes, with a mean medication-free IOP of $12.8 \pm 4 \mathrm{mmHg}$ and PS in 53 (21.8\%) eyes, with a final IOP of $15.0 \pm 3 \mathrm{mmHg}$ and $1.5 \pm 1$ medications. Four eyes in the failure group required another tube surgery and nine eyes underwent diode laser treatment to achieve the target IOP.

Table I Sociodemographic and Clinical Data

\begin{tabular}{|c|c|c|c|c|c|c|c|}
\hline Age (years) & \multicolumn{2}{|c|}{ Failure $(\mathbf{N}=\mathbf{3} \mathrm{I})$} & \multicolumn{2}{|c|}{ Qualified Success (N = 212) } & \multicolumn{2}{|c|}{ Total $(N=243)$} & \multirow{2}{*}{$\begin{array}{l}P \text { value } \\
0.1693\end{array}$} \\
\hline & & & & & & & \\
\hline Mean (SD) & 56.2 & $(19)$ & 60.6 & $(16)$ & 60.1 & $(17)$ & \\
\hline Median (IQR) & 56 & $(4 I ; 7 I)$ & 63 & $(52 ; 73)$ & 63 & $(51 ; 73)$ & \\
\hline Min-Max & & $22-87$ & & $18-92$ & & $18-92$ & \\
\hline Sex, (\%) & & & & & & & 0.2955 \\
\hline Male & 14 & $(45.2)$ & 117 & $(55.2)$ & $|3|$ & $(53.9)$ & \\
\hline Female & 17 & $(54.8)$ & 95 & $(44.8)$ & 112 & $(46.1)$ & \\
\hline Follow-up time (months), & & & & & & & 0.9216 \\
\hline Mean (SD) & 69.7 & $(76)$ & 66.4 & (63) & 66.8 & (64) & \\
\hline Median (IQR) & 44.3 & $(23 ; 84)$ & 44.4 & $(22 ; 93)$ & 44.3 & $(22 ; 92)$ & \\
\hline Study eye, (\%) & & & & & & & 0.6794 \\
\hline Right eye & 16 & $(51.6)$ & 101 & $(47.6)$ & 117 & $(48.1)$ & \\
\hline Left eye & 15 & $(48.4)$ & 111 & $(52.4)$ & 126 & (5I.9) & \\
\hline
\end{tabular}

Notes: Ages compared using the Student's t-test (normal distribution checked). Sex and study eye compared using the Chi ${ }^{2}$ test. Follow-up time: comparison performed using the Wilcoxon test (distribution not normal). There were no significant between-group differences regarding age, sex, and follow-up time.

Abbreviations: SD, standard deviation; IQR, interquartile range. 
We consider three exceptions: Patients number 53, 32, and 381 who, despite not achieving a $20 \%$ decrease in IOP, reached their target pressures between 6 and $21 \mathrm{mmHg}$ and the withdrawal of the three drugs to which they were local and systemically intolerant were therefore regarded as success cases.

There were no significant differences between the failure and QS groups $(p=0.0879)$ and between the CS and PS groups ( $p=0.3746$ ) with respect to changes in visual acuity three months after surgery. One line of vision was gained in $52(21.7 \%)$ eyes and lost in $19(7.9 \%)$ eyes. More than one line was lost in $45(18.8 \%)$ eyes.

None of the known risk factors for trabeculectomy failure studied were associated with the probability of achieving QS versus failure (Table 2), although comparison of the PS and CS groups showed some significant differences (Table 3).

Follow-up time was significantly longer in the PS group than in the CS group $(62.4 \pm 63$ vs. $78.2 \pm 61$ months, $p=0.0117$ ). Eyes with a higher mean preoperative IOP had a lower final IOP. With respect to aetiologies, NVG significantly attained CS in $88.46 \%$ of the QS, whereas the other types of glaucoma showed a higher proportion of PS over CS cases $(p=0.0022)$.

With respect to the effect of previous surgeries that changed the ocular anatomy and conjunctival conditions, naive eyes achieved CS in 60 (84.5\%) eyes compared with 98 $(70 \%)$ of previously operated eyes $(p=0.0217)$. Univariate analysis showed a higher risk of a requirement for glaucoma medication in eyes with previous surgery (OR $0.428 ; 95 \% \mathrm{CI}$ $0.205-0.894 ; p=0.0240$ ). Eyes with DPM required fewer hypotensive drugs than DPSI with a silicone plate $(p=0.0095)$ (Table 4), but the multivariate model did not show the implant type was a risk factor for PS (OR 3.593; 95\% CI 0.969-13.313; $p=0.0557$ ).

Almost all patients were on maximum medical treatment before surgery (median of 3 and mean of $3 \pm 1$ drug administered via a median of five drops for all three groups). Comparison of the CS and PS groups showed significant differences in the use of two drugs: atropine $(p=0.0022)$ and brimonidine $(p=0.0034)$. The logistic multivariate model adjusted for aetiology, implant type, and HP did not show an increased probability of CS with the preoperative use of atropine, while preoperative treatment with brimonidine showed a higher probability of PS than CS (OR 0.318; 95\% CI 0.108-0.94; $p=0.0383$ ) when adjusted for glaucoma type, implant type, and preoperative atropine treatment.
Forty-eight eyes (19.8\%) had HP: 10 (32.3\%) failed eyes, 18 (34\%) PS eyes, and 20 (12.6\%) CS eyes $(p=0.0004)$. Multivariate analysis adjusted for aetiology, implant type, and preoperative atropine treatment showed that HP was associated with a $66.3 \%$ reduction in the odds of CS (OR 0.331; 95\% CI 0.127-0.866; $p=0.0242$ ).

Analysis of the differences between eyes with and without HP showed a significantly higher rate of HP when some risk factors were present (Table 5).

HP was seen in 9 (10.2\%) eyes with NVG, 9 (19.1\%) aphakic eyes with or without anterior chamber IOL, 10 $(22.2 \%)$ eyes with previous complicated intraocular surgery, 4 (25.0\%) Uveitic eyes, 9 (32.1\%) eyes with previous failed glaucoma surgery, and $7(36.8 \%)$ cases with juvenile/congenital/syndromic glaucoma $(p=0.0390)$. Tube location in the posterior chamber $(p<0.0001)$, double-plate silicone implant $(p<0.0001)$, and a history of previous ocular surgery $(p=0.0012)$ were associated with a higher frequency of HP, while a higher preoperative IOP was associated with a lower incidence of HP $(p=0.0057)$. The number of preoperative drugs were similar in both groups: mean \pm SD $3 \pm 1$; median 3; and range 0-5. Preoperative use of prostaglandin analogs, carbonic anhydrase inhibitors and brimonidine was significantly associated with HP, but preoperative atropine, beta-blocker, and dipivalilepinephrine were associated with a lower frequency of HP (Table 6).

Logistic multivariate analysis, adjusted for aetiology, implant type, and preoperative atropine use, identified the following predictors of HP: posterior chamber location of the tube (OR 3.561; 95\% CI 1.286-9.861; $p=0.0145$ ) and preoperative use of prostaglandin analogs (OR 4.286; 95\% CI 1.593-11.529; $p=0.0039$ ). The rate of complications related to the GDD implantation and complications that have not been considered derived from the implant surgery are listed in Tables 7 and 8 .

\section{Discussion}

The results of this study show that double-plate implant surgery is very effective in lowering IOP in refractory glaucoma, with a QS rate of $87.3 \%$ at 5 years. We did not include eyes with light perception loss, postoperative hypotonia, or any other complication not due to implant surgery or the tube per se, which may be the reason for the low percentage of failures compared with other studies that reported a QS of $60.5 \%$ based on similar success criteria. ${ }^{11}$ In our study, tube surgery resulted in IOP reductions of $60.8 \%$ to a postoperative mean IOP of $14.6 \pm 6.3$ 
Table 2 Determination of Failure and Qualified Success by Comparison of the Risk Factors Studied

\begin{tabular}{|c|c|c|c|c|c|c|c|}
\hline $\begin{array}{l}\text { Preoperative IOP } \\
\text { Mean (SD) }\end{array}$ & \multicolumn{2}{|c|}{ Failure $(\mathbf{N}=31)$} & \multicolumn{2}{|c|}{ Qualified Success $(N=2 \mid 2)$} & \multicolumn{2}{|c|}{ Total $(N=243)$} & \multirow{2}{*}{$\begin{array}{l}P \text { value } \\
0.8605\end{array}$} \\
\hline $\begin{array}{l}\text { Mean (SD) } \\
\text { Median (IQR) } \\
\text { Min - Max }\end{array}$ & $\begin{array}{l}36.9 \\
36\end{array}$ & $\begin{array}{l}(13) \\
(24 ; 482) \\
18-60\end{array}$ & $\begin{array}{l}37.3 \\
35\end{array}$ & $\begin{array}{l}(13) \\
(28 ; 46) \\
12-72\end{array}$ & $\begin{array}{l}37.3 \\
35\end{array}$ & $\begin{array}{l}(13) \\
(26 ; 46) \\
12-72\end{array}$ & \\
\hline $\begin{array}{l}\text { Etiology, } \mathbf{n}(\%) \\
\text { NVG } \\
\text { Juvenile/congenital glaucoma and syndromes } \\
\text { Aphakia/pseudophakia and AC IOL } \\
\text { Previous failed glaucoma surgery } \\
\text { Penetrant keratoplasty/trauma/complicated intraocular surgery } \\
\text { Uveitis }\end{array}$ & $\begin{array}{l}10 \\
5 \\
5 \\
6 \\
3 \\
2\end{array}$ & $\begin{array}{l}(32.3) \\
(16.1) \\
(16.1) \\
(19.4) \\
(9.7) \\
(6.5)\end{array}$ & $\begin{array}{l}78 \\
14 \\
42 \\
22 \\
42 \\
14\end{array}$ & $\begin{array}{l}(36.8) \\
(6.6) \\
(19.8) \\
(10.4) \\
(19.8) \\
(6.6)\end{array}$ & $\begin{array}{l}88 \\
19 \\
47 \\
28 \\
45 \\
16\end{array}$ & $\begin{array}{l}(36.2) \\
(7.8) \\
(19.3) \\
(11.5) \\
(18.5) \\
(6.6)\end{array}$ & 0.2248 \\
\hline $\begin{array}{l}\text { Tube localization, } \mathbf{n}(\%) \\
\text { AC } \\
\text { PC }\end{array}$ & $\begin{array}{l}15 \\
16\end{array}$ & $\begin{array}{l}(48.4) \\
(51.6)\end{array}$ & $\begin{array}{l}114 \\
98\end{array}$ & $\begin{array}{l}(53.8) \\
(46.2)\end{array}$ & $\begin{array}{l}129 \\
114\end{array}$ & $\begin{array}{l}(53.1) \\
(46.9)\end{array}$ & 0.5746 \\
\hline $\begin{array}{l}\text { Type of implant, no. (\%) } \\
\text { Double-plate Molteno }{ }^{\circledR} \text { Ophthalmic (Dunedin) } \\
\text { Double-plate implant (FCl S.A.S Paris, France) }\end{array}$ & $\begin{array}{l}15 \\
16\end{array}$ & $\begin{array}{l}(48.4) \\
(51.6)\end{array}$ & $\begin{array}{l}84 \\
128\end{array}$ & $\begin{array}{l}(39.6) \\
(60.4)\end{array}$ & $\begin{array}{l}99 \\
144\end{array}$ & $\begin{array}{l}(40.7) \\
(59.3)\end{array}$ & 0.3536 \\
\hline $\begin{array}{l}\text { Categorized previous surgery, no. (\%) } \\
\text { No previous surgery } \\
\text { Previous surgery }\end{array}$ & $\begin{array}{l}8 \\
23\end{array}$ & $\begin{array}{l}(25.8) \\
(74.2)\end{array}$ & $\begin{array}{l}71 \\
140\end{array}$ & $\begin{array}{l}(33.6) \\
(66.4)\end{array}$ & $\begin{array}{l}79 \\
163\end{array}$ & $\begin{array}{l}(32.6) \\
(67.4)\end{array}$ & 0.3845 \\
\hline $\begin{array}{l}\text { Number of previous surgeries, no. } \\
\text { Missing data, no. } \\
\text { Mean (SD) } \\
\text { Median (IQR) } \\
\text { Min - Max }\end{array}$ & $\begin{array}{l}0 \\
1.7 \\
2\end{array}$ & $\begin{array}{l}(2) \\
(0 ; 2) \\
0-13\end{array}$ & $\begin{array}{l}1 \\
1.4 \\
1\end{array}$ & $\begin{array}{l}(2) \\
(0 ; 2) \\
0-9\end{array}$ & $\begin{array}{l}1 \\
1.5 \\
1\end{array}$ & $\begin{array}{l}(2) \\
(0 ; 2) \\
0-13\end{array}$ & \\
\hline $\begin{array}{l}\text { Hypertensive phase, no. (\%) } \\
\text { No } \\
\text { Yes }\end{array}$ & $\begin{array}{l}21 \\
10\end{array}$ & $\begin{array}{l}(67.7) \\
(32.3)\end{array}$ & $\begin{array}{l}174 \\
38\end{array}$ & $\begin{array}{l}(82.1) \\
(17.9)\end{array}$ & $\begin{array}{l}195 \\
48\end{array}$ & $\begin{array}{l}(80.2) \\
(19.8)\end{array}$ & 0.0612 \\
\hline $\begin{array}{l}\text { Treatment before surgery (compounds), no. } \\
\text { Mean (SD) } \\
\text { Median (IQR) } \\
\text { Min-Max }\end{array}$ & $\begin{array}{l}3 \\
3\end{array}$ & $\begin{array}{l}(1) \\
(3 ; 3) \\
2-4\end{array}$ & $\begin{array}{l}3 \\
3\end{array}$ & $\begin{array}{l}(1) \\
(3 ; 3) \\
0-5\end{array}$ & $\begin{array}{l}3 \\
3\end{array}$ & $\begin{array}{l}(1) \\
(3 ; 3) \\
0-5\end{array}$ & \\
\hline $\begin{array}{l}\text { Number of eyedrops before surgery, no. } \\
\text { Missing data, no } \\
\text { Mean (Std) } \\
\text { Median (IQR) } \\
\text { [Min - Max] }\end{array}$ & $\begin{array}{l}1 \\
4.7 \\
5\end{array}$ & $\begin{array}{l}(2) \\
(4 ; 5) \\
{[2-7]}\end{array}$ & $\begin{array}{l}18 \\
4.5 \\
5\end{array}$ & $\begin{array}{l}(1) \\
(4 ; 5) \\
{[0-8]}\end{array}$ & $\begin{array}{l}19 \\
4.5 \\
5\end{array}$ & $\begin{array}{l}(1) \\
(4 ; 5) \\
{[0-8]}\end{array}$ & 0.3568 \\
\hline $\begin{array}{l}\text { Preoperative atropine, no. (\%) } \\
\text { No } \\
\text { Yes }\end{array}$ & $\begin{array}{l}22 \\
8\end{array}$ & $\begin{array}{l}(73.3) \\
(26.7)\end{array}$ & $\begin{array}{l}132 \\
62\end{array}$ & $\begin{array}{l}(68.0) \\
(32.0)\end{array}$ & $\begin{array}{l}154 \\
70\end{array}$ & $\begin{array}{l}(68.8) \\
(31.3)\end{array}$ & 0.5606 \\
\hline $\begin{array}{l}\text { Preoperative beta-blockers, no. (\%) } \\
\text { No } \\
\text { Yes }\end{array}$ & $\begin{array}{l}2 \\
28\end{array}$ & $\begin{array}{l}(6.7) \\
(93.3)\end{array}$ & $\begin{array}{l}13 \\
181\end{array}$ & $\begin{array}{l}(6.7) \\
(93.3)\end{array}$ & $\begin{array}{l}15 \\
209\end{array}$ & $\begin{array}{l}(6.7) \\
(93.3)\end{array}$ & 1.0000 \\
\hline $\begin{array}{l}\text { Preoperative PGA, no. (\%) } \\
\text { No } \\
\text { Yes }\end{array}$ & $\begin{array}{l}25 \\
5\end{array}$ & $\begin{array}{l}(83.3) \\
(16.7)\end{array}$ & $\begin{array}{l}154 \\
38\end{array}$ & $\begin{array}{l}(80.2) \\
(19.8)\end{array}$ & $\begin{array}{l}179 \\
43\end{array}$ & $\begin{array}{l}(80.6) \\
(19.4)\end{array}$ & 0.6871 \\
\hline
\end{tabular}

(Continued) 
Table 2 (Continued).

\begin{tabular}{|c|c|c|c|c|c|c|c|}
\hline \multirow{2}{*}{ Preoperative CAI, no. (\%) } & \multicolumn{2}{|c|}{ Failure $(\mathbf{N}=31)$} & \multicolumn{2}{|c|}{ Qualified Success ( $N=212$ ) } & \multicolumn{2}{|c|}{ Total $(N=243)$} & \multirow{2}{*}{$\begin{array}{l}\boldsymbol{P} \text { value } \\
0.8877\end{array}$} \\
\hline & & & & & & & \\
\hline No & 21 & $(70.0)$ & 134 & (68.7) & 155 & (68.9) & \\
\hline Yes & 9 & $(30.0)$ & 61 & $(31.3)$ & 70 & $(31.1)$ & \\
\hline Preoperative brimonidine, no. (\%) & & & & & & & 0.5338 \\
\hline No & 23 & (76.7) & 154 & $(81.5)$ & 177 & (80.8) & \\
\hline Yes & 7 & $(23.3)$ & 35 & $(18.5)$ & 42 & $(19.2)$ & \\
\hline Preoperative dipivalil-epinephrine, no. (\%) & & & & & & & 0.4316 \\
\hline No & 13 & (43.3) & 96 & $(51.1)$ & 109 & $(50.0)$ & \\
\hline Yes & 17 & (56.7) & 92 & (48.9) & 109 & $(50.0)$ & \\
\hline Preoperative pilocarpine, no. (\%) & & & & & & & 1.0000 \\
\hline No & 27 & $(90.0)$ & 167 & (88.8) & 194 & $(89.0)$ & \\
\hline Yes & 3 & $(10.0)$ & 21 & $(11.2)$ & 24 & $(11.0)$ & \\
\hline
\end{tabular}

Notes: Comparison of study eye, tube localization, previous surgery, preoperative atropine, prostaglandins analogues, topical carbonic anhydrase inhibitor, brimonidine and dipivalil-epinephrine treatment performed using the $\mathrm{Chi}^{2}$ test. Comparison of etiology and beta-blockers and pilocarpine preoperative treatment performed using the Fisher's exact test. There is no significant difference between the two groups regarding distribution of all the risk factors studied.

Abbreviations: NVG, neovascular glaucoma; AC IOL, anterior chamber intraocular lens; AC, anterior chamber; PC, posterior chamber; SD, standard deviation; IQR, interquartile; PGA, prostaglandin analogs; CAl, carbonic anhydrase inhibitor.

Table 3 Determination of Partial Success and Complete Success by Comparison of the Risk Factors Studied

\begin{tabular}{|c|c|c|c|c|c|c|c|}
\hline \multirow{3}{*}{$\begin{array}{l}\text { Preoperative IOP no. } \\
\text { Mean (SD) }\end{array}$} & \multicolumn{2}{|c|}{ Complete Success $(N=159)$} & \multicolumn{2}{|c|}{ Partial Success $(\mathbf{N}=\mathbf{5 3})$} & \multicolumn{2}{|c|}{ Total $(\mathbf{N}=2 \mid 2)$} & \multirow{2}{*}{$\begin{array}{l}P \text { value } \\
0.0054\end{array}$} \\
\hline & & & & & & & \\
\hline & 38.8 & $(14)$ & 33 & (II) & 37.3 & $(13)$ & \\
\hline Median (IQR) & 38 & $(28 ; 50)$ & 32 & $(25 ; 37)$ & 35 & $(28 ; 46)$ & \\
\hline Min-Max & - & $12-72$ & - & $15-64$ & - & $12-72$ & \\
\hline Aetiology, no. (\%) & & & & & & & 0.0022 \\
\hline NVG & 69 & $(43.4)$ & 9 & $(17.0)$ & 78 & $(36.8)$ & \\
\hline Juvenile/congenital glaucoma and syndromes & 8 & $(5.0)$ & 6 & $(11.3)$ & 14 & $(6.6)$ & \\
\hline Aphakia/pseudophakia and AC IOL & 31 & $(19.5)$ & 11 & $(20.8)$ & 42 & $(19.8)$ & \\
\hline Previous failed glaucoma surgery & 12 & $(7.5)$ & 10 & $(18.9)$ & 22 & $(10.4)$ & \\
\hline Penetrant keratoplasty/trauma/complicated & 31 & $(19.5)$ & 11 & $(20.8)$ & 42 & $(19.8)$ & \\
\hline Intraocular surgery & & & & & & & \\
\hline Uveitis & 8 & $(5,0)$ & 6 & $(11.3)$ & 14 & $(6.6)$ & \\
\hline Previous ocular surgery, no. (\%) & & & & & & & 0.0217 \\
\hline No previous surgery & 60 & $(38.0)$ & 11 & $(20.8)$ & 71 & $(33.6)$ & \\
\hline Previous surgery & 98 & $(62.0)$ & 42 & $(79.2)$ & 140 & $(66.4)$ & \\
\hline Hypertensive phase, no. (\%) & & & & & & & 0.0004 \\
\hline No & 139 & $(87.4)$ & 35 & $(66.0)$ & 174 & $(82.1)$ & \\
\hline Yes & 20 & $(12.6)$ & 18 & $(34.0)$ & 38 & $(17.9)$ & \\
\hline Preoperative atropine, no. (\%) & & & & & & & 0.0022 \\
\hline No & 93 & $(62.4)$ & 39 & $(86.7)$ & 132 & $(68.0)$ & \\
\hline Yes & 56 & $(37.6)$ & 6 & $(13.3)$ & 62 & $(32.0)$ & \\
\hline Preoperative brimonidine, no. (\%) & & & & & & & 0.0 .0034 \\
\hline No & 124 & $(86.1)$ & 30 & $(66.7)$ & 154 & $(81.5)$ & \\
\hline Yes & 20 & $(13.9)$ & 15 & $(33.3)$ & 35 & $(18.5)$ & \\
\hline
\end{tabular}

Notes: Preoperative IOP and aetiology compared using Fisher's exact test. Previous surgery, hypertensive phase, and preoperative atropine and brimonidine compared using the $\mathrm{Chi}^{2}$ test.

Abbreviations: NVG, neovascular glaucoma; SD, standard deviation; IQR, interquartile range; AC IOL, anterior chamber intraocular lens; IOP, intraocular pressure. 
Table 4 Determination of Partial Success and Complete Success by Implant Characteristics and Intraocular Location

\begin{tabular}{|c|c|c|c|c|c|c|c|}
\hline Tube location, no. (\%) & \multicolumn{2}{|c|}{ Complete Success $(N=159)$} & \multicolumn{2}{|c|}{ Partial Success $(\mathbf{N}=\mathbf{5 3})$} & \multicolumn{2}{|c|}{ Total $(\mathbf{N}=212)$} & $\begin{array}{l}\boldsymbol{P} \text { value } \\
0.8736\end{array}$ \\
\hline Anterior chamber & 86 & (54.1) & 28 & (52.8) & 114 & (53.8) & \\
\hline Posterior chamber & 73 & $(45.9)$ & 25 & $(47.2)$ & 98 & $(46.2)$ & \\
\hline Type of implant, no. (\%) & & & & & & & 0.0095 \\
\hline Double-plate Molteno ${ }^{\circledR}$ Ophthalmic (Dunedin) & 71 & (44.7) & 13 & $(24.5)$ & 84 & (39.6) & \\
\hline Double-plate silicone implant (FCI S.A.S., France) & 88 & $(55.3)$ & 40 & (75.5) & 128 & $(60.4)$ & \\
\hline
\end{tabular}

Notes: Implant type and tube location compared using the chi ${ }^{2}$ test. There was a significant difference between the two groups regarding the type of implant.

Table 5 Determination of the Hypertensive Phase by Comparison of the Risk Factors Studied

\begin{tabular}{|c|c|c|c|c|c|c|c|}
\hline \multirow[b]{2}{*}{ Preoperative IOP } & \multicolumn{2}{|c|}{ No $(H P)(N=195)$} & \multicolumn{2}{|c|}{ Yes $(H P)(N=48)$} & \multicolumn{2}{|c|}{ Total $(N=243)$} & \multirow{2}{*}{$\begin{array}{l}P \text { value } \\
0.0057\end{array}$} \\
\hline & 38.4 & $(13)$ & 32.6 & $(13)$ & 37.3 & $(13)$ & \\
\hline Previous surgery, no.(\%) & & & & & & & 0.0012 \\
\hline No previous surgery & 73 & $(37.4)$ & 6 & $(12.8)$ & 79 & $(32.6)$ & \\
\hline Previous surgery & 122 & $(62.6)$ & 41 & $(87.2)$ & 163 & $(67.4)$ & \\
\hline Aetiology, no. (\%) & & & & & & & 0.0390 \\
\hline NVG & 79 & $(40.5)$ & 9 & $(18.8)$ & 88 & $(36.2)$ & \\
\hline Juvenile congenital glaucoma and syndromes & 12 & $(6.2)$ & 7 & $(14.6)$ & 19 & $(7.8)$ & \\
\hline Aphakia/pseudophakia AC IOL & 38 & $(19.5)$ & 9 & $(18.8)$ & 47 & $(19.3)$ & \\
\hline Previous failed glaucoma surgery & 19 & $(9.7)$ & 9 & $(18.8)$ & 28 & $(11.5)$ & \\
\hline Penetrant keratoplasty/trauma/complicated intraocular surgery & 35 & $(17.9)$ & 10 & $(20.8)$ & 45 & $(18.5)$ & \\
\hline Uveitis & 12 & $(6.2)$ & 4 & $(8.3)$ & 16 & $(6.6)$ & \\
\hline Tube localization, no. (\%) & & & & & & & $<0.0001$ \\
\hline $\mathrm{AC}$ & 117 & $(60.0)$ & 12 & $(25.0)$ & 129 & $(53.1)$ & \\
\hline $\mathrm{PC} /$ retroiris & 78 & $(40.0)$ & 36 & $(75.0)$ & 114 & $(46.9)$ & \\
\hline Type of implant, no. (\%) & & & & & & & $<0.0001$ \\
\hline Double-plate Molteno ${ }^{\circledR}$ Ophthalmic (Dunedin) & 95 & $(48.7)$ & 4 & $(8.3)$ & 99 & $(40.7)$ & \\
\hline Double-plate silicone implant (FCI S.A.S France) & 100 & $(51.3)$ & 44 & $(91.7)$ & 144 & $(59.3)$ & \\
\hline
\end{tabular}

Notes: Preoperative IOP compared using the Student's $t$-test (normal distribution checked). Aetiology, tube location and type of implant compared using the Chi ${ }^{2}$ test. There was a significant difference between the two groups regarding preoperative IOP, distribution of the aetiology, tube location, and type of implant. Abbreviations: NVG, neovascular glaucoma; AC IOL, anterior chamber intraocular lens; AC, anterior chamber; PC, posterior chamber.

mmHg on $0.4 \pm 1$ medications. Likewise, Thompson et al reported similar results, with a probability of IOP control below $21 \mathrm{mmHg}$ of 0.79 (95\% $\mathrm{Cl} ; 0.71-0.87)$, and a mean IOP of $14.5 \pm 3.4 \mathrm{mmHg}$ on 0.7 medications. ${ }^{12}$

We found significant differences between the CS and PS groups regarding the type of glaucoma, which is frequently a heterogeneous factor in other reports. Some authors have reported, although in smaller series, that the type of glaucoma is a predictor of the success of borderline significance $(p=0.09) .{ }^{13}$ In contrast with studies in which neovascular glaucoma achieved lower success rates (40-53\%), we found that NVG needed fewer anti-glaucoma medications than other types of glaucoma, with $88.6 \%$ achieving QS and $88.5 \%$ of those achieving CS. ${ }^{11,13,14}$ A possible explanation is that some
NVG eyes developed hypotony or lost light perception due to retinal detachment (not associated with the implant), long after the tube surgery, and therefore we did not consider them as failures, unlike other studies that did. ${ }^{13}$

In these eyes, there is lower aqueous humour inflow due to reduced production rates as a consequence of the chronic ischemic status of the ciliary body. The same rationale may explain why the group with a miscellaneous condition (complicated previous intraocular surgery and severe trauma) had such a high QS rate (93.3\%), of whom 73.8\% achieved CS, confirming the impression of previous studies that verify that drainage implants are especially efficient in traumatic eyes. ${ }^{15}$

The expression of inflammation mediators from the cytokine interleukin family increases in the aqueous humour of 
Table 6 Determination of the Hypertensive Phase by Comparison of Topical Treatment

\begin{tabular}{|c|c|c|c|c|c|c|c|}
\hline \multirow[b]{2}{*}{ Preoperative treatment, no. } & \multicolumn{2}{|c|}{ No $(N=195)$} & \multicolumn{2}{|c|}{ Yes $(N=48)$} & \multicolumn{2}{|c|}{ Total $(N=243)$} & \multirow[t]{5}{*}{$P$ value } \\
\hline & 195 & & 48 & & 243 & & \\
\hline Mean (SD) & 3 & (I) & 3 & (I) & 3 & (I) & \\
\hline Median (IQR) & 3 & $(3 ; 3)$ & 3 & $(3 ; 3)$ & 3 & $(3 ; 3)$ & \\
\hline Min-Max & & $0-5$ & & $0-5$ & & $0-5$ & \\
\hline Preoperative atropine, no. (\%) & & & & & & & 0.0003 \\
\hline No & 116 & $(63.4)$ & 38 & (92.7) & 154 & $(68.8)$ & \\
\hline Yes & 67 & $(36.6)$ & 3 & (7.3) & 70 & $(3 \mid .3)$ & \\
\hline Preoperative beta-blockers, no. (\%) & & & & & & & 0.0362 \\
\hline No & 9 & $(4.9)$ & 6 & $(14.6)$ & 15 & $(6.7)$ & \\
\hline Yes & 174 & $(95.1)$ & 35 & $(85.4)$ & 209 & $(93.3)$ & \\
\hline Prostaglandin analogues, no. (\%) & & & & & & & $<0.0001$ \\
\hline No & 159 & $(87.4)$ & 20 & $(50.0)$ & 179 & $(80.6)$ & \\
\hline Yes & 23 & $(12.6)$ & 20 & $(50.0)$ & 43 & $(19.4)$ & \\
\hline Preoperative topical carbonic anhydrase inhibitor & & & & & & & 0.0004 \\
\hline No & 135 & $(74.2)$ & 20 & $(46.5)$ & 155 & $(68.9)$ & \\
\hline Yes & 47 & $(25.8)$ & 23 & $(53.5)$ & 70 & $(3 I .1)$ & \\
\hline Preoperative brimonidine, no. (\%) & & & & & & & $<0.0001$ \\
\hline No & 155 & $(86.1)$ & 22 & $(56.4)$ & 177 & $(80.8)$ & \\
\hline Yes & 25 & $(13.9)$ & 17 & $(43.6)$ & 42 & $(19.2)$ & \\
\hline Preoperative dipivalil-epinephrine, no. (\%) & & & & & & & $<0.0001$ \\
\hline No & 76 & $(42.5)$ & 33 & $(84.6)$ & 109 & $(50.0)$ & \\
\hline Yes & 103 & $(57.5)$ & 6 & $(15.4)$ & 109 & $(50.0)$ & \\
\hline Preoperative pilocarpine, no. (\%) & & & & & & & 0.5823 \\
\hline No & 158 & $(88.3)$ & 36 & $(92.3)$ & 194 & $(89.0)$ & \\
\hline Yes & 21 & $(11.7)$ & 3 & $(7.7)$ & 24 & $(I I .0)$ & \\
\hline
\end{tabular}

Notes: Atropine, prostaglandin analogues, topical carbonic anhydrase inhibitor, brimonidine and dipivalil-epinephrine compared using the Chi ${ }^{2}$ test. Beta-blockers and pilocarpine compared using Fisher's exact test. There was a significant difference between the two groups regarding all preoperative drops except for pilocarpine. Abbreviations: SD, standard deviation; IQR, interquartile range.

certain types of glaucoma such as uveitic glaucoma. ${ }^{16}$ This stimulates the fibroproliferative process and increases trabeculectomy failure rates. ${ }^{17}$ However, in our series, tube surgery was resistant to active intraocular inflammation, with $87.5 \%$ of QS in uveitic glaucoma. These results are in agreement with those of other studies with QS rates between $75 \%$ and $89.5 \%$ and suggest that GDD surgery in patients with uveitis has a similar effect on IOP as in patients without uveitis. ${ }^{11,13,18,19}$ Nevertheless, the uveitic group in our study showed less IOP control than other aetiologies, since only $57.1 \%$ of the QS eyes achieved CS.

Various studies have investigated the efficacy of GDD in developmental glaucoma, but the few that used double-plate implants reported differing results, with success rates ranging from $100 \%$ to $59 \% .^{20,21} \mathrm{Ah}$-Chan reported a probability of achieving an IOP below $21 \mathrm{mmHg}$ of 0.71 (95\% CI
$0.58-0.85)$ at 15 years of follow-up, with no mention of hypotensive treatment, similar to the $73.7 \%$ of QS in our series. $^{22}$

Previous conjunctival surgery for glaucoma or any other type of surgery with conjunctival scarring is considered a strong risk factor for trabeculectomy failure, but was not a risk factor for tube surgery failure in our study, in concordance with other authors, although it did affect the ultimate need for hypotensive agents. ${ }^{11,13}$

In our study, 47 aphakic and pseudophakic eyes had an unexpected QS rate of $89.4 \%$, in contrast to smaller series with lower success rates (58-78\%), but, in which, the type of cataract extraction technique or intraoperative complications plausibly affecting overall glaucoma surgery success were not described. ${ }^{13,22}$ 
Table 7 Complications Related to the GDD

\begin{tabular}{|l|l|}
\hline Fibrine clot & $17(22)$ \\
Persistent corneal oedema & $9(I 1.7)$ \\
Corneal graft rejection & $6(7.8)$ \\
Shallow or flat anterior chamber & $6(7.8)$ \\
Diplopia & $6(7.8)$ \\
Tube repositioning & $6(7.8)$ \\
Choroidal effusion & $4(5.2)$ \\
Suprachoroidal haemorrhage & $3(3.9)$ \\
Aqueous misdirection & $3(3.9)$ \\
Cystoid macular oedema & $3(3.9)$ \\
Tube exposure & $3(3.9)$ \\
Tube retraction & $2(2.6)$ \\
Tube obstruction & $2(2.6)$ \\
Dellen & $2(2.6)$ \\
Sterile endophthalmitis & $2(2.6)$ \\
Plate exposure & $2(2.6)$ \\
Severe hypema (>50\%) & $2(2.6)$ \\
Tube breakage & $I(I .3)$ \\
Tube explantation & $I(I .3)$ \\
Total number of patients with complications related to the GDD* & 77 \\
\hline
\end{tabular}

Notes: *Some patients had more that I complication. Data presented in number of patients (percentage).

Table 8 Complications Not Related to the GDD

\begin{tabular}{|l|l|}
\hline Retinal detachment/PVR & $34(70.8)$ \\
Vitreous haemorrhage & $3(6.2)$ \\
Epiretinal membrane & $3(6.2)$ \\
Corneal ulcer/abscess & $3(6.2)$ \\
Orbital cellulitis & $2(4.1)$ \\
Age related maculopathy & $\mathrm{I}(2)$ \\
Corneal stromal haemorrhage & $\mathrm{I}(2)$ \\
Neovascular subretinal membrane & $\mathrm{I}(2)$ \\
Total number of patients with complications not related to the GDD* & 48 \\
\hline
\end{tabular}

Notes: *Some patients had more that I complication. Data presented in number of patients (percentage).

High-pressure glaucoma is associated with higher levels of proinflammatory cytokines and thicker filtering capsules, which are predictors of poor success rates. ${ }^{23}$ However, we found high preoperative IOP and preoperative atropine treatment were more prevalent in the CS group, possibly because both conditions are frequent in NVG, the most favoured glaucoma type regarding CS. However, logistic multivariate analysis did not confirm the increased probability of CS with preoperative use of atropine (OR 3.003; 95\% Cl 0.674, 13.38; $p=0.1493$ ) and should be considered a confounder.

Richter et al established the first relationship between encapsulated trabeculectomy blebs and chronic use of hypotensive eye drops. ${ }^{24} \mathrm{We}$ found no relationship between preoperative topical treatment and failure, since almost all eyes were on maximum hypotensive therapy; however, we found differences in the types of drugs used preoperatively and the need for hypotensive medication postoperatively.

There was a direct prognostic relationship with the use of brimonidine, which reduced the CS by $68.2 \%$, in agreement with studies that demonstrated that its chronic use causes inflammatory changes in conjunctival cellularity. ${ }^{25}$

Until 2006, the Cochrane review found no advantages between commercially available implants. ${ }^{26}$ More recently, a pooled data analysis showed some differences between valved and non-valved drainage systems but no differences have been detected between non-valved implants of similar dimensions. ${ }^{12,27,28}$ In the current study, the same surgeon, implant design, surgical technique, and flow restrictive measures ensured procedural homogeneity. With respect to the two implant models, DPM has a circular polypropylene endplate and the DPSI circular plates are similar but made of flexible silicone. In vitro studies have shown that polypropylene seems to result in the least adherence of cultured Tenon fibroblasts and an animal model registered slightly higher inflammatory infiltrates than did silicone plates. ${ }^{29,30}$ The material of the two implants in the current study showed no differences regarding success or failure rates, but the silicone one was related to the use of more postoperative glaucoma medications.

The aqueous permeability of the mature capsule depends on the delicate balance between the fibroproliferative and fibro-degenerative processes that occur around the plates during the early postoperative period and seems to be affected by early contact with the aqueous humour. ${ }^{31,32}$ HP may be considered a consequence of an excessive intramural inflammatory reaction during capsular development, which would be decisive regarding the final permeability. We found that HP was related to a $67 \%$ increase in the probability of PS versus CS, in agreement with another report in which a significantly greater proportion of eyes with HP after Ahmed valve surgery required additional glaucoma surgery compared with eyes without HP. ${ }^{33}$ In our study, $19.8 \%$ of cases had HP, in accordance with the known prevalence in Molteno implants (20-30\%), and in contrast with the Ahmed valve, which is more frequently associated with this complication $(82 \%)$, as in valved implants there is an immediate contact between the aqueous humour and the subconjunctival tissue. ${ }^{34,35}$

Prostaglandin analogs, which increase cytokines levels, could also be a key factor in stimulating the inflammatory infiltration that precedes scarring. ${ }^{36}$ However, in our very 
homogeneous surgical scenario, prostaglandin analogues did not appear to be a direct risk factor for PS as was brimonidine, but they increased the probability of HP fourfold, which in turn is a risk factor for PS.

The same was observed when the tube was located in the posterior chamber which, despite not being a risk factor for surgery failure, as other reports suggested, seems to be a risk factor for HP, as it requires iris manipulation such as peripheral iridectomy, which increases intraocular inflammation. ${ }^{37-39}$ Surprisingly, unlike other reports, we found that preoperative IOP was lower in eyes with HP $(p=0.0057)$. HP during the early postoperative period predicts the future need for long-term hypotensive medication, which may be prevented by reported measures such as the early initiation of aqueous suppressant therapy to avoid capsular stretching, antifibrotic treatments to modulate future capsular development and permeability and, in some cases, the use of MMC intraoperatively if it is considered beforehand. Once HP becomes established, improvement is less likely and the need for hypotensive medication is greater. $^{15,40-44}$ Study limitations: This is a retrospective design. All patients were Caucasian which limits the generalizability of the study and the therapies for some of the populations studied (NVG and uveitis glaucoma) have changed in the past 25 years with newer anti-VEGF agents, newer steroids, and immunomodulating therapies. The two drainage implants used have the same design but different material. However, the tight handling of the variables, the proactive control of patients throughout the follow-up, and the use of a similar surgical technique and follow-up by the same surgeon diminished the bias.

In conclusion, we found that glaucoma surgery with drainage implants is minimally affected by risk factors for trabeculectomy failure, making the double-plate drainage implant a robust and predictable surgical technique that is useful in most glaucomatous eyes with poor surgical prognoses. Some types of glaucoma, i.e., NVG, aphakic glaucoma, and eyes with previous complex ocular surgery achieved better results with respect to the need for glaucoma medication in the long run.

\section{Abbreviations}

IOP, intraocular pressure; MMC, mitomycin C; GDD, glaucoma drainage devices; $\mathrm{AGV}$, Ahmed glaucoma valve; BCVA, best-corrected visual acuity; NVG, neovascular glaucoma; VEGF, vascular endothelial growth factor; HP, hypertensive phase.

\section{Funding}

Laboratoires Théa provided funds for the statistical study of the data.

\section{Disclosure}

Dr Susana Duch reports financial help for statistical study from Thea Laboratoires, during the conduct of the study; personal fees from Thea, personal fees from Bausch Lomb, outside the submitted work; Dr Carlos A. Arciniegas-Perasso report non-financial support from Laboratorios Théa, during the conduct of the study. The authors report no other conflicts of interest in this work.

\section{References}

1. Gedde SJ, Schiffman JC, Feuer WJ, et al. Treatment outcomes in the tube versus trabeculectomy (TVT) study after five years of follow-up. Am J Ophthalmol. 2012;153(5):789-803.e2. doi:10.1016/j.ajo.2011.10.026

2. Vinod K, Gedde SJ, Feuer WJ, et al. Practice preferences for glaucoma surgery: a survey of the American glaucoma society. J Glaucoma. 2017;26(8):687-693. doi:10.1097/IJG.0000000000000720

3. Tseng VL, Coleman AL, Chang MY, Caprioli J. Aqueous shunts for glaucoma. Cochrane Database Syst Rev. 2017;7. doi:10.1002/ 14651858.CD004918.pub3

4. Gedde SJ, Feuer WJ, Shi W, et al. Treatment outcomes in the primary tube versus Trabeculectomy Study after 1 year of follow-up. Ophthalmology. 2018;125(5):650-663. doi:10.1016/j.ophtha.20 18.02.003

5. Molteno ACB, Suter AJ, Fenwick M, Bevin TH, Dempster AG. Otago glaucoma surgery outcome study: cytology and immunohistochemical staining of bleb capsules around molteno implants. Invest Ophthalmol Vis Sci. 2006;47(5):1975-1981. doi:10.1167/iovs.05-0988

6. Molteno ACB, Bevin TH, Dempster AG, Sarris M, McCluskey P. Otago glaucoma surgery outcome study: cytology and immunohistochemistry of trabeculectomy blebs. Invest Ophthalmol Vis Sci. 2013;54(7):4991-4999. doi:10.1167/iovs.12-11553

7. Chen CW. Enhanced intraocular pressure controlling effectiveness of trabeculectomy by local application of mitomycin-c. Trans Asia Pac Acad Ophthalmol. 1983;9:172-177.

8. Cantor L, Burgoyne J, Sanders S, Bhavnani V, Hoop J, Brizendine E. The effect of mitomycin $\mathrm{C}$ on molteno implant surgery: a 1-year randomized, masked, prospective study. J Glaucoma. 1998;7 (4):240-246. doi:10.1097/00061198-199808000-00005

9. Leng F, Liu P, Li H, Zhang J. Long-term topical antiglaucoma medications cause enhanced Tenon's capsule fibroblast proliferation and abnormal TGF- $\beta$ and MMP expressions: potential effects on glaucoma filtering surgery. Curr Eye Res. 2011;36(4):301-309. doi: $10.3109 / 02713683.2010 .547648$

10. Bettin P, Khaw PT, eds. Glaucoma Surgery. 2nd. Vol. 59. Karger; 2017. AG2017ISSN0250-3751

11. Broadway DC, Iester M, Schulzer M, Douglas GR. Survival analysis for success of molteno tube implants. $\mathrm{Br} J$ Ophthalmol. 2001;85 (6):689-695. doi:10.1136/bjo.85.6.689

12. Thompson AM, Molteno ACB, Bevin TH, Herbison P. Otago Glaucoma Surgery Outcome Study. Comparative results for the 175-mm2 molteno3 and double-plate molteno implants. JAMA Ophthalmol. 2013;131(2):155-159. doi:10.1097/00132578-20000400 0-00014

13. Mills RP, Reynolds A, Emond MJ, Barlow WE, Leen MM. Longterm survival of molteno glaucoma drainage devices. Ophthalmology. 1996;103(2):299-305. doi:10.1016/S0161-6420(96)30700-8 
14. Every SG, Molteno ACB, Bevin TH, Herbison P. Long-term results of molteno implant insertion in cases of neovascular glaucoma. Arch Ophthalmol. 2006;124:355-360. doi:10.1001/archopht.124.3.355

15. Fuller JR, Bevin TH, Molteno ACB. Long-term follow-up of traumatic glaucoma treated with molteno implants. Ophthalmology. 2001;108(10):1796-1800. doi:10.1016/S0161-6420(01)00714-X

16. Ohira S, Inoue $\mathrm{T}$, Iwao $\mathrm{K}$, Takahashi $\mathrm{E}$, Tanihara $\mathrm{H}$, Acott TS. Factors influencing aqueous proinflammatory cytokines and growth factors in uveitic glaucoma. PLoS One. 2016;11(1):1-13. doi:10.1371/journal.pone.0147080

17. Chono I, Miyazaki D, Miyake H, Komatsu N, Ehara F. High interleukin-8 level in aqueous humor is associated with poor prognosis in eyes with open angle glaucoma and neovascular glaucoma. Sci Rep. 2018;8(1):1. doi:10.1038/s41598-018-32725-3

18. Molteno ACB, Sayawat N, Herbison P. Otago Glaucoma Surgery Outcome Study. Long-term Results of uveitis with secondary glaucoma drained by molteno implants. Ophthalmology. 2001;108 (3):605-613. doi:10.1016/S0161-6420(00)00594-7

19. Ramdas WD, Pals J, Rothova A, Wolfs RCW. Efficacy of glaucoma drainage devices in uveitic glaucoma and a meta-analysis of the literature. Graefe's Arch Clin Exp Ophthalmol. 2019;257:143-151. doi:10.1007/s00417-018-4156-9

20. Goldberg I. Management of uncontrolled glaucoma with the molteno system. Aust N Z J Ophthalmol. 1987;15(2):97-107. doi:10.1111/ j.1442-9071.1987.tb00053.x

21. Nesher R, Sherwood M, Kass M, Hines J, Kolker A. Molteno implants in children. J Glaucoma. 1992;1(4):228-232. doi:10.1097/ 00061198-199201040-00003

22. Ah-Chan JJ, Molteno ACB, Bevin TH, Herbison P. Otago Glaucoma Surgery Outcome Study. Follow-up of young patients who underwent molteno implant surgery. Ophthalmology. 2005;112(12):2137-2142. doi:10.1016/j.ophtha.2005.07.011

23. Freedman J, Iserovich P. Pro-inflammatory cytokines in glaucomatous aqueous and encysted molteno implant blebs and their relationship to pressure. Invest Ophthalmol Vis Sci. 2013;54(7):4851-4855. doi:10.1167/iovs.13-12274

24. Richter CU, Shingleton BJ, Bellows AR, Hutchinson BT, O'Connor T, Brill I. The development of encapsulated filtering blebs. Ophthalmology. 1988;95(9):1163-1168. doi:10.1016/S01616420(88)33041-1

25. Arthur S, Cantor LB. Update on the role of alpha-agonists in glaucoma management. Exp Eye Res. 2011;93(3):271-283. doi:10.1016/j. exer.2011.04.002

26. Minckler D, Vedula S, Li T, Mathew M, Ayyala R, Francis B. Aqueous shunts for glaucoma (review). Cochrane Database Syst Rev. 2006;2. doi:10.1002/14651858.CD004918.pub2

27. Smith MF, Doyle JW, Sherwood MB. Comparison of the baerveldt glaucoma implant with the double-plate molteno drainage implant. Arch Ophthalmol. 1995;113(4):444-447. doi:10.1001/archopht.199 5.01100040060027

28. Christakis PG, Zhang D, Budenz DL, Barton K, Tsai JC, Ahmed IIK. Five-year pooled data analysis of the Ahmed Baerveldt Comparison Study and the Ahmed Versus Baerveldt Study. Am J Ophthalmol. 2017;176:118-126. doi:10.1016/j.ajo.2017.01.003

29. Choritz L, Koynov K, Renieri G, Barton K, Pfeiffer N, Thieme H. Surface topographies of glaucoma drainage devices and their influence on human tenon fibroblast adhesion. Invest Ophthalmol Vis Sci. 2010;51:4047-4053. doi:10.1167/iovs.09-4759
30. Duch S. El tratamiento del glaucoma refractario con los distintos implantes de drenaje: modelo experimental [Thesis]. 1995. C:199596-BDD:09504118F/ETS

31. Molteno ACB, Thompson AM, Bevin TH, Dempster AG. Otago glaucoma surgery outcome study: tissue matrix breakdown by apoptotic cells in capsules surrounding molteno implants. Invest Ophthalmol Vis Sci. 2009;50(3):1187-1197. doi:10.1167/iovs.07-1424

32. Molteno ACB, Fucik M, Dempster AG, Bevin TH. Otago Glaucoma Surgery Outcome Study: factors controlling capsule fibrosis around molteno implants with histopathological correlation. Ophthalmology. 2003;110(11):2198-2206. doi:10.1016/S0161-6420(03)00803-0

33. Law SK, Kornmann HL, Giaconi JA, Kwong A, Tran E, Caprioli J. Early aqueous suppressant therapy on hypertensive phase following glaucoma drainage device procedure: a randomized prospective trial. J Glaucoma. 2016;25(3):248-257. doi:10.1097/IJG.00000000 00000131

34. Ayyala RS, Zurakowski D, Monshizadeh R, et al. Comparison of double-plate molteno and ahmed glaucoma valve in patients with advanced uncontrolled glaucoma. Ophthalmic Surg Lasers. 2002;33 (2):94-101.

35. Ayyala RS, Zurakowski D, Smith JA, et al. A clinical study of the ahmed glaucoma valve implant in advanced glaucoma. Ophthalmology. 1998;105(10):1968-1976. doi:10.1016/S01616420(98)91049-1

36. Koh SWM, Coll TJ, Rose L, Matsumoto Y, Higginbotham EJ. Antiglaucoma eye drop pulses - increased interleukin-6 secretion by Tenon's capsule fibroblast cultures. $J$ Glaucoma. 2004;13 (3):200-209. doi:10.1097/00061198-200406000-00005

37. Weiner A, Cohn AD, Balasubramaniam M, Weiner AJ. Glaucoma tube shunt implantation through the ciliary sulcus in pseudophakic eyes with high risk of corneal decompensation. J Glaucoma. 2010;19 (6):405-411. doi:10.1097/IJG.0b013e3181bdb52d

38. Luke SK. Complications of peripheral iridectomy. Can J Ophthalmol. 1969;4(4):346-351.

39. Aketa N, Yamaguchi T, Suzuki T, et al. Iris damage is associated with elevated cytokine levels in aqueous humor. Invest Ophthalmol Vis Sci. 2017;58(6):BIO42-BIO51. doi:10.1167/iovs.17-21421

40. Molteno ACB, Straughan JL, Ancker E. Control of bleb fibrosis after glaucoma surgery by anti-inflammatory agents. S Afr Med J. 1976;50 (23):881-885.

41. Fargione RA, Tansuebchueasai N, Lee R, Tania Tai TY. Etiology and management of the hypertensive phase in glaucoma drainage-device surgery. Surv Ophthalmol. 2019;64(2):217-224. doi:10.1016/j. survophthal.2018.10.008

42. Pakravan M, Rad SS, Yazdani S, Ghahari E, Yaseri M. Effect of early treatment with aqueous suppressants on ahmed glaucoma valve implantation outcomes. Ophthalmology. 2014;121:1693-1698. doi:10.1016/j.ophtha.2014.03.014

43. Ellingham RB, Morgan WH, Westlake W, House PH. Mitomycin $\mathrm{C}$ eliminates the short-term intraocular pressure rise found following molteno tube implantation. Clin Exp Ophthalmol. 2003;31 (3):191-198. doi:10.1046/j.1442-9071.2003.00644.x

44. Nouri-Mahdavi K, Caprioli J. Evaluation of the hypertensive phase after insertion of the ahmed glaucoma valve. Am J Ophthalmol. 2003;136(6):1001-1008. doi:10.1016/S0002-9394(03)00630-5 


\section{Publish your work in this journal}

Clinical Ophthalmology is an international, peer-reviewed journal covering all subspecialties within ophthalmology. Key topics include: Optometry; Visual science; Pharmacology and drug therapy in eye diseases; Basic Sciences; Primary and Secondary eye care; Patient Safety and Quality of Care Improvements. This journal is indexed on PubMed
Central and CAS, and is the official journal of The Society of Clinical Ophthalmology (SCO). The manuscript management system is completely online and includes a very quick and fair peer-review system, which is all easy to use. Visit http://www.dovepress.com/ testimonials.php to read real quotes from published authors. 